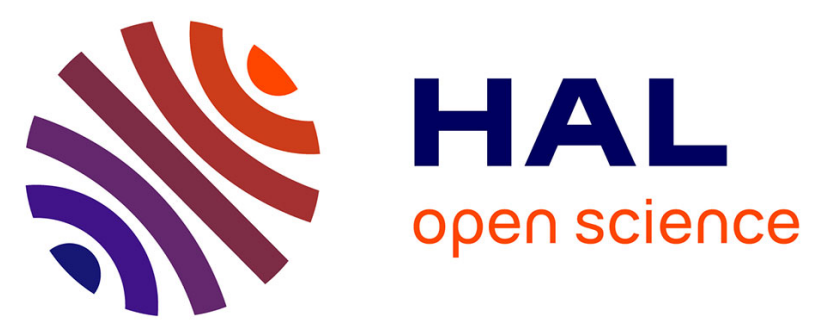

\title{
Empagliflozin in the treatment of heart failure with reduced ejection fraction in addition to background therapies and therapeutic combinations (EMPEROR-Reduced): a post-hoc analysis of a randomised, double-blind trial
}

Subodh Verma, Nitish Dhingra, Javed Butler, Stefan Anker, Joao Pedro Ferreira, Gerasimos Filippatos, James Januzzi, Carolyn Lam, Naveed Sattar, Barbara Peil, et al.

\section{To cite this version:}

Subodh Verma, Nitish Dhingra, Javed Butler, Stefan Anker, Joao Pedro Ferreira, et al.. Empagliflozin in the treatment of heart failure with reduced ejection fraction in addition to background therapies and therapeutic combinations (EMPEROR-Reduced): a post-hoc analysis of a randomised, double-blind trial. The Lancet. Diabetes \& Endocrinology , 2021, 10.1016/S2213-8587(21)00292-8 . hal-03470953

\section{HAL Id: hal-03470953 \\ https://hal.science/hal-03470953}

Submitted on 10 Dec 2021

HAL is a multi-disciplinary open access archive for the deposit and dissemination of scientific research documents, whether they are published or not. The documents may come from teaching and research institutions in France or abroad, or from public or private research centers.
L'archive ouverte pluridisciplinaire HAL, est destinée au dépôt et à la diffusion de documents scientifiques de niveau recherche, publiés ou non, émanant des établissements d'enseignement et de recherche français ou étrangers, des laboratoires publics ou privés. 


\title{
Empagliflozin in the treatment of heart failure with reduced ejection fraction in addition to background therapies and therapeutic combinations (EMPEROR-Reduced): a post-hoc analysis of a randomised, double-blind trial
}

Subodh Verma, Nitish K Dhingra, Javed Butler, Stefan D Anker, Joao Pedro Ferreira, Gerasimos Filippatos, James L Januzzi, Carolyn S P Lam, Naveed Sattar, Barbara Peil, Matias Nordaby, Martina Brueckmann, StuartJ Pocock, Faiez Zannad, Milton Packer, on behalf of the EMPERORReduced trial committees and investigators*

\begin{abstract}
Summary
Background It is important to evaluate whether a new treatment for heart failure with reduced ejection fraction (HFrEF) provides additive benefit to background foundational treatments. As such, we aimed to evaluate the efficacy and safety of empagliflozin in patients with HFrEF in addition to baseline treatment with specific doses and combinations of disease-modifying therapies.
\end{abstract}

Methods We performed a post-hoc analysis of the EMPEROR-Reduced randomised, double-blind, parallel-group trial, which took place in 520 centres (hospitals and medical clinics) in 20 countries in Asia, Australia, Europe, North America, and South America. Patients with New York Heart Association (NYHA) classification II-IV with an ejection fraction of $40 \%$ or less were randomly assigned (1:1) to receive the addition of either oral empagliflozin $10 \mathrm{mg}$ per day or placebo to background therapy. The primary composite outcome was cardiovascular death and heart failure hospitalisation; the secondary outcome was total heart failure hospital admissions. An extended composite outcome consisted of inpatient and outpatient HFrEF events was also evaluated. Outcomes were analysed according to background use of angiotensinconverting enzyme (ACE) inhibitors, angiotensin II receptor blockers (ARBs) or angiotensin receptor neprilysin inhibitors (ARNIs), as well as $\beta$ blockers and mineralocorticoid receptor antagonists (MRAs) at less than $50 \%$ or $50 \%$ or more of target doses and in various combinations. This study is registered with ClinicalTrials.gov, NCT03057977.

Findings In this post-hoc analysis of 3730 patients (mean age 66.8 years [SD 11.0], 893 [23.9\%] women; 1863 [49.9\%] in the empagliflozin group, 1867 [50.1\%] in the placebo group) assessed between March 6, 2017, and May 28, 2020, empagliflozin reduced the risk of the primary outcome (361 in 1863 participants in the empagliflozin group and 462 of 1867 in the placebo group; HR 0.75 [95\% CI 0.65-0 86]) regardless of background therapy or its target doses for ACE inhibitors or ARBs at doses of less than $50 \%$ of the target dose (HR 0.85 [0.69-1.06]) and for doses of $50 \%$ or more of the target dose (HR 0.67 [0.52-0.88]; $p_{\text {interaction }}=0.18$ ). A similar result was seen for $\beta$ blockers at doses of less than $50 \%$ of the target dose (HR $0.66[0 \cdot 54-0 \cdot 80])$ and for doses of $50 \%$ or more of the target dose (HR $\left.0 \cdot 81[0 \cdot 66-1 \cdot 00] ; p_{\text {interaction }}=0 \cdot 15\right)$. Empagliflozin also reduced the risk of the primary outcome irrespective of background use of triple therapy with an ACE inhibitor, ARB, or ARNI plus $\beta$ blocker plus MRA (given combination HR 0.73 [0.61-0.88]; not given combination HR $\left.0.76[0 \cdot 62-0.94] ; p_{\text {interation }}=0.77\right)$. Similar patterns of benefit were observed for the secondary and extended composite outcomes. Empagliflozin was well tolerated and rates of hypotension, symptomatic hypotension, and hyperkalaemia were similar across all subgroups.

Interpretation Empagliflozin reduced serious heart failure outcomes across doses and combinations of diseasemodifying therapies for HFrEF. Clinically, these data suggest that empagliflozin might be considered as a foundational therapy in patients with HFrEF regardless of their existing background therapy.

Funding Boehringer Ingelheim and Eli Lilly and Company.

\section{Introduction}

A common scenario in the medical treatment of heart failure with reduced ejection fraction (HFrEF) is the inability to achieve target doses of guideline-directed medical therapy, ${ }^{1,2}$ which results in therapeutic regimens of varying doses of each life-saving therapy. As each trial assessing treatments thus far has focused on optimising their doses to the target, ambiguity remains about the benefit of prescribing new therapies to individuals not receiving target doses of the background treatments. ${ }^{3}$ In the EMPEROR-Reduced trial, empagliflozin reduced the incidence of cardiovascular death or heart failure hospitalisation in patients with HFrEF compared with placebo. ${ }^{4}$ In addition, empagliflozin reduced total
Division of Cardiac Surgery, St Michael's Hospital, University of Toronto, Toronto, ON, Canada (Prof S Verma MD, N K Dhingra BHSc); Department of Medicine, University of Mississippi School of Medicine, Jackson, MS, USA

(ProfJ Butler MD); Department of Cardiology and Berlin Institute of Health Center for Regenerative Therapies, German Centre for Cardiovascular Research Partner Site Berlin, Charité Universitätsmedizin, Berlin, Germany (Prof S D Anker MD); Centre d'Investigations Cliniques Plurithématique 1433, Université de Lorraine, Institut National de la Santé et de la Recherche Médicale 1116, Centre Hospitalier Régional Universitaire de Nancy, French Clinical Research Infrastructure Network, Investigation Network InitiativeCardiovascular and Renal Clinical Trialists, Nancy, France (J P Ferreira MD, Prof F Zannad MD); Cardiovascular Research and Development Center Department of Surgery and Physiology, Faculty of Medicine of the University of Porto, Porto, Portugal (J P Ferreira); National and Kapodistrian University of Athens School of Medicine, Athens University Hospital Attikon, Athens, Greece (G Filippatos MD); Division of Cardiology, Harvard 
Medical School and Massachusetts General Hospital, Boston, MA, USA (J L Januzzi MD); National Heart Centre Singapore, DukeNational University of

Singapore Medical School, Singapore (Prof C S P Lam MD); Institute of Cardiovascular and Medical Sciences, University of Glasgow, Glasgow, UK (Prof N Sattar MD); Boehringer Ingelheim Pharma, Ingelheim,

Germany (B Peil DrSc hum); Boehringer Ingelheim International, Ingelheim, Germany (M Nordaby MD,

M Brueckmann MD); Faculty of Medicine Mannheim, University of Heidelberg, Mannheim, Germany (M Brueckmann); Department of Medical Statistics, London School of Hygiene and Tropical Medicine, London, UK (Prof SJ Pocock PhD); Baylor Heart and Vascular Institute,

Baylor University Medical Center, Dallas, TX, USA (Prof M Packer MD); Imperial College London, London, UK (Prof M Packer)

Correspondence to: Prof Subodh Verma, Division of Cardiac Surgery, St Michael's Hospital, University of Toronto, Toronto, ON, M5B 1W8, Canada subodh.verma@unityhealth.to

\section{Research in context}

\section{Evidence before this study}

It is important to evaluate whether a new therapy for heart failure with reduced ejection fraction (HFrEF) affords clinically meaningful benefits in addition to established disease-modifying therapies. We searched MEDLINE from database inception up until July 12, 2021, using a string of key words including "sodiumglucose transporter 2 inhibitors", "heart failure", and "HFrEF" to identify articles that assessed cardiovascular outcomes with SGLT2 inhibitors stratified by background therapy, using data from randomised trials. The search was not limited to articles in English. We identified one such analysis from the DAPA-HF trial, showing dapagliflozin's efficacy, and none regarding empagliflozin. In the EMPEROR-Reduced trial, empagliflozin reduced the incidence of cardiovascular death or heart failure hospitalisations in patients with HFrEF compared with placebo. The trial did not mandate specific doses or specific drugs of background heart failure therapies and hence there is an opportunity to determine if the benefits of empagliflozin are influenced by established disease-modifying therapies, when used in combination and when prescribed at target or sub-target doses.

\section{Added value of this study}

The present study extends similar analyses previously conducted on dapagliflozin in DAPA-HF through the inclusion of additional clinically relevant subgroups, and the evaluation of the key secondary and extended composite outcomes. In particular, we studied the efficacy of empagliflozin versus placebo in patients given less than $50 \%$ and $50 \%$ or more of target doses of angiotensin-converting enzyme inhibitors or angiotensin II receptor blockers, $\beta$ blockers, and mineralocorticoid receptor antagonists. In addition, the treatment effect was evaluated according to whether or not patients were receiving one of five therapeutic combinations at baseline. We found that empagliflozin reduced the primary outcome regardless of background therapy or its target doses, and irrespective of background use of dual and triple therapy combinations. Similar patterns of benefit were observed for the secondary and extended composite outcomes.

\section{Implications of all the available evidence}

These data indicate that empagliflozin provides clinically important benefits in HFrEF in addition to existing diseasemodifying therapies, regardless of breadth or intensity of use. This observation points to a complementary mechanism of action in HFrEF and suggests that four-drug treatment is associated with benefit, even if sub-target doses of each therapy are used. hospitalisation for heart failure and serious adverse renal outcomes, while improving functional class and health status, effects that were seen in patients with and without diabetes. ${ }^{47}$

The EMPEROR-Reduced trial required patients to be treated for heart failure, but did not mandate specific doses or specific drugs. Consequently, the trial provided an opportunity to determine if the benefits of empagliflozin are influenced by established diseasemodifying therapies when used in combination and when prescribed at target or sub-target doses, as similarly evaluated with dapagliflozin in the DAPA-HF trial. ${ }^{8.9}$ Conventional inhibitors of the renin-angiotensin system (angiotensin-converting enzyme [ACE] inhibitors, angiotensin II receptor blockers [ARBs], angiotensin receptor neprilysin inhibitors [ARNIs]), $\beta$ blockers, and mineralocorticoid receptor antagonists (MRAs) are established treatments for HFrEF. As such, in this post-hoc analysis, we aimed to evaluate the efficacy and safety of empagliflozin in patients given these foundational drug classes, used alone or in combination or prescribed at $50 \%$ or greater or at less than $50 \%$ of target dose.

\section{Methods}

\section{Study design and participants}

In brief, in EMPEROR-Reduced, patients with heart failure and left ventricular ejection fraction (LVEF) of
$40 \%$ or less and NYHA functional class II-IV symptoms were randomly assigned $(1: 1)$ to double-blind oral treatment with either placebo or empagliflozin $10 \mathrm{mg}$ daily, which was added to background therapy.,10 520 centres (hospitals and medical clinics) in 20 countries in Asia, Australia, Europe, North America, and South America were involved in the trial. ${ }^{4}$ To prioritise the recruitment of patients at high risk, participants were required to have markedly elevated $\mathrm{N}$-terminal pro B-type natriuretic peptide (NT-proBNP), the exact threshold for which depended on ejection fraction. The NT-proBNP inclusion criteria were $600 \mathrm{pg} / \mathrm{mL}$ or greater in patients with a LVEF of $30 \%$ or less, $1000 \mathrm{pg} / \mathrm{mL}$ or greater in patients with a LVEF of $31-35 \%$, and $2500 \mathrm{pg} / \mathrm{mL}$ or greater in patients with a LVEF of $36-40 \%$; patients could also participate with an NT-proBNP of $600 \mathrm{pg} / \mathrm{mL}$ or greater if they had an LVEF of $40 \%$ or less and been hospitalised for heart failure within the past 12 months. These NT-proBNP thresholds were doubled in patients with atrial fibrillation. Treatments for heart failure could be added, withdrawn, or modified during follow-up, according to the discretion of individual physicians. The key exclusion criteria were symptomatic hypotension or a systolic blood pressure of less than $100 \mathrm{~mm} \mathrm{Hg}$ and estimated glomerular filtration rate (eGFR) less than $20 \mathrm{~mL} / \mathrm{min}$ per $1.73 \mathrm{~m}^{2}$. Each trial centre's respective ethics committee approved the trial, and written 
informed consent was provided by all patients. Further details are available in the design ${ }^{10}$ and primary publications. ${ }^{4}$

\section{Outcomes}

The primary endpoint of EMPEROR-Reduced was the composite of time-to-first of hospitalisation for heart failure or cardiovascular death. The main secondary outcome was the occurrence of total (first and recurrent) hospitalisations for heart failure. To capture out-ofhospital worsening heart failure events, we defined an extended composite of cardiovascular death, hospitalisation for heart failure, urgent visits for worsening heart failure requiring intravenous therapy, and interval outpatient intensification of oral diuretic therapy for treatment of worsening heart failure.?

\begin{tabular}{|c|c|c|c|c|c|c|}
\hline & \multicolumn{2}{|l|}{ ACE inhibitors or ARBs } & \multicolumn{2}{|l|}{$\beta$ blockers } & \multicolumn{2}{|l|}{ MRAs } \\
\hline & $\begin{array}{l}\geq 50 \% \text { of target dose } \\
(n=1191)\end{array}$ & $\begin{array}{l}<50 \% \text { of target dose } \\
(n=1375)\end{array}$ & $\begin{array}{l}\geq 50 \% \text { of target dose } \\
(n=1825)\end{array}$ & $\begin{array}{l}<50 \% \text { of target dose } \\
(n=1708)\end{array}$ & $\begin{array}{l}\geq 50 \% \text { of target dose } \\
(n=2601)\end{array}$ & $\begin{array}{l}<50 \% \text { of target dose } \\
(n=60)\end{array}$ \\
\hline Age, years & $65.9(10 \cdot 7)$ & $67 \cdot 4(10 \cdot 9)$ & $65 \cdot 9(10 \cdot 9)$ & $67 \cdot 8(11.0)$ & $65 \cdot 7(11 \cdot 1)$ & $67 \cdot 2(9 \cdot 8)$ \\
\hline \multicolumn{7}{|l|}{ Sex } \\
\hline Male & $884(74 \cdot 2 \%)$ & $1060(77 \cdot 1 \%)$ & $1378(75 \cdot 5 \%)$ & $1300(76 \cdot 1 \%)$ & $1956(75 \cdot 2 \%)$ & $50(83 \cdot 3 \%)$ \\
\hline Female & $307(25 \cdot 8 \%)$ & $315(22 \cdot 9 \%)$ & $447(24 \cdot 5 \%)$ & $408(23.9 \%)$ & $645(24 \cdot 8 \%)$ & $10(16 \cdot 7 \%)$ \\
\hline \multicolumn{7}{|l|}{ Race $^{*}$} \\
\hline $\begin{array}{l}\text { American Indian or } \\
\text { Native Alaskan }\end{array}$ & $9(0.8 \%)$ & $20(1 \cdot 5 \%)$ & $11(0.6 \%)$ & $24(1 \cdot 4 \%)$ & $30(1 \cdot 2 \%)$ & 0 \\
\hline Asian & $57(4 \cdot 8 \%)$ & $367(26 \cdot 7 \%)$ & $116(6 \cdot 4 \%)$ & $486(28 \cdot 5 \%)$ & $429(16 \cdot 5 \%)$ & $23(38 \cdot 3 \%)$ \\
\hline $\begin{array}{l}\text { Black or African } \\
\text { American }\end{array}$ & $143(12 \cdot 0 \%)$ & $70(5 \cdot 1 \%)$ & $203(11 \cdot 1 \%)$ & $100(5 \cdot 9 \%)$ & $222(8 \cdot 5 \%)$ & 0 \\
\hline $\begin{array}{l}\text { Hawaiian or Pacific } \\
\text { Islander }\end{array}$ & $5(0 \cdot 4 \%)$ & $5(0.4 \%)$ & $5(0 \cdot 3 \%)$ & $8(0.5 \%)$ & $9(0 \cdot 3 \%)$ & 0 \\
\hline White & $995(83 \cdot 5 \%)$ & $928(67 \cdot 5 \%)$ & $1496(82 \cdot 0 \%)$ & $1091(63.9 \%)$ & $1920(73.8 \%)$ & $36(60.0 \%)$ \\
\hline Missing & $7(0.6 \%)$ & $9(0.7 \%)$ & $35(1.9 \%)$ & $19(1.1 \%)$ & $43(1.7 \%)$ & $1(1 \cdot 7 \%)$ \\
\hline \multicolumn{7}{|l|}{ Ethnicity } \\
\hline Hispanic or Latino & $575(48 \cdot 3 \%)$ & $369(26 \cdot 8 \%)$ & $733(40 \cdot 2 \%)$ & $446(26 \cdot 1 \%)$ & $974(37 \cdot 4 \%)$ & $7(11.7 \%)$ \\
\hline Not Hispanic or Latino & $557(46 \cdot 8 \%)$ & $957(69 \cdot 6 \%)$ & $988(54 \cdot 1 \%)$ & $1217(71 \cdot 3 \%)$ & $1508(58 \cdot 0 \%)$ & $51(85 \cdot 0 \%)$ \\
\hline Missing & $59(5 \cdot 0 \%)$ & $49(3 \cdot 6 \%)$ & $104(5 \cdot 7 \%)$ & $45(2 \cdot 6 \%)$ & $119(4 \cdot 6 \%)$ & $2(3.3 \%)$ \\
\hline \multicolumn{7}{|c|}{ New York Heart Association functional classification } \\
\hline ॥ & $910(76 \cdot 4 \%)$ & $1056(76 \cdot 8 \%)$ & $1367(74 \cdot 9 \%)$ & $1288(75 \cdot 4 \%)$ & $1939(74 \cdot 5 \%)$ & $46(76 \cdot 7 \%)$ \\
\hline III & $272(22 \cdot 8 \%)$ & $315(22 \cdot 9 \%)$ & $447(24 \cdot 5 \%)$ & $412(24 \cdot 1 \%)$ & $648(24 \cdot 9 \%)$ & $13(21 \cdot 7 \%)$ \\
\hline IV & $9(0.8 \%)$ & $4(0.3 \%)$ & $11(0.6 \%)$ & $8(0.5 \%)$ & $14(0.5 \%)$ & $1(1.7 \%)$ \\
\hline Baseline KCCQ-CSS & $68 \cdot 3(22 \cdot 0)$ & $73 \cdot 0(21 \cdot 3)$ & $69 \cdot 3(22 \cdot 3)$ & $72 \cdot 2(21 \cdot 5)$ & $70 \cdot 1(22 \cdot 2)$ & $74 \cdot 4(19 \cdot 5)$ \\
\hline $\begin{array}{l}\text { Heart rate, beats per } \\
\text { minute }\end{array}$ & $70 \cdot 4(11 \cdot 4)$ & $72 \cdot 4(12 \cdot 0)$ & $70 \cdot 7(11 \cdot 8)$ & $71.5(11.5)$ & $71 \cdot 2(11 \cdot 7)$ & $71 \cdot 4(12 \cdot 3)$ \\
\hline $\begin{array}{l}\text { Systolic blood pressure, } \\
\mathrm{mm} \mathrm{Hg}\end{array}$ & $125 \cdot 9(16 \cdot 4)$ & $121 \cdot 4(15 \cdot 1)$ & $122 \cdot 2(15 \cdot 8)$ & $121 \cdot 7(15 \cdot 5)$ & $120 \cdot 7(15 \cdot 2)$ & $122 \cdot 2(17 \cdot 4)$ \\
\hline $\begin{array}{l}\text { Left ventricular ejection } \\
\text { fraction }\end{array}$ & $27 \cdot 7(5 \cdot 7)$ & $27 \cdot 4(6 \cdot 2)$ & $27 \cdot 4(6 \cdot 1)$ & $27 \cdot 6(6 \cdot 0)$ & $27 \cdot 1(6 \cdot 0)$ & $27 \cdot 4(5 \cdot 9)$ \\
\hline $\begin{array}{l}\text { Median NT-proBNP, } \\
\mathrm{pg} / \mathrm{mL}\end{array}$ & $1828 \cdot 0(1059 \cdot 0-3125 \cdot 0)$ & $1937 \cdot 5(1131 \cdot 0-3612 \cdot 0)$ & $1865 \cdot 0(1070 \cdot 5-3357 \cdot 0)$ & $1931 \cdot 0(1142 \cdot 5-3569 \cdot 0)$ & $1866 \cdot 0(1074 \cdot 0-3349 \cdot 0)$ & $1989 \cdot 0(1210 \cdot 0-3414 \cdot 5)$ \\
\hline \multicolumn{7}{|l|}{ Cardiovascular history } \\
\hline $\begin{array}{l}\text { Hospitalisation for } \\
\text { heart failure in the } \\
\text { past } 12 \text { months }\end{array}$ & $302(25 \cdot 4 \%)$ & $444(32 \cdot 3 \%)$ & $501(27 \cdot 5 \%)$ & $590(34 \cdot 5 \%)$ & $842(32 \cdot 4 \%)$ & $25(41 \cdot 7 \%)$ \\
\hline Atrial fibrillation $\dagger$ & $377(31 \cdot 7 \%)$ & $548(39 \cdot 9 \%)$ & $705(38.6 \%)$ & $590(34 \cdot 5 \%)$ & $918(35 \cdot 3 \%)$ & $21(35 \cdot 0 \%)$ \\
\hline Diabetes‡ & 608 (51.0\%) & $664(48 \cdot 3 \%)$ & $936(51 \cdot 3 \%)$ & $822(48 \cdot 1 \%)$ & $1271(48 \cdot 9 \%)$ & $29(48 \cdot 3 \%)$ \\
\hline $\begin{array}{l}\text { Estimated glomerular } \\
\text { filtration rate, } \mathrm{mL} / \mathrm{min} \\
\text { per } 1.73 \mathrm{~m}^{2}\end{array}$ & $63.4(21 \cdot 2)$ & $62 \cdot 4(21 \cdot 7)$ & $61.5(21.6)$ & $62 \cdot 5(21 \cdot 6)$ & $63.9(21 \cdot 6)$ & $62 \cdot 3(20 \cdot 1)$ \\
\hline $\begin{array}{l}\text { Data are mean (SD), } \mathrm{n}(\%) \text {, o } \\
\text { Questionnaire Clinical Summ } \\
\text { therefore, the total percenta } \\
\text { ¥Defined as investigator rep }\end{array}$ & $\begin{array}{l}\text { edian (IQR). } \mathrm{ACE}=\text { angioten } \\
\text { Score. NT-proBNP=N-tern } \\
\text { might be more than } 100 \% \text {. } \\
\text { ed or pretreatment } \mathrm{HbA}_{1 \mathrm{c}} \text { of }\end{array}$ & $\begin{array}{l}\text {-converting enzyme. ARB }= \\
\text { al pro-brain natriuretic pep } \\
\text { efined as atrial fibrillation } \\
5 \% \text { or greater. }\end{array}$ & $\begin{array}{l}\text { iotensin II receptor blocker. I } \\
\text { "For each race category, all } \\
\text { rted in any electrocardiograr }\end{array}$ & $\begin{array}{l}\text { MRA=mineralocorticoid rece } \\
\text { I respondents are counted, in } \\
\text { m before treatment intake } 0\end{array}$ & $\begin{array}{l}r \text { antagonist. KCCQ-CSS=Kans } \\
\text { ding those who marked multi } \\
\text { tory of atrial fibrillation repor }\end{array}$ & $\begin{array}{l}\text { ssas City Cardiomyopathy } \\
\text { tiple race categories; } \\
\text { orted in medical history. }\end{array}$ \\
\hline
\end{tabular}




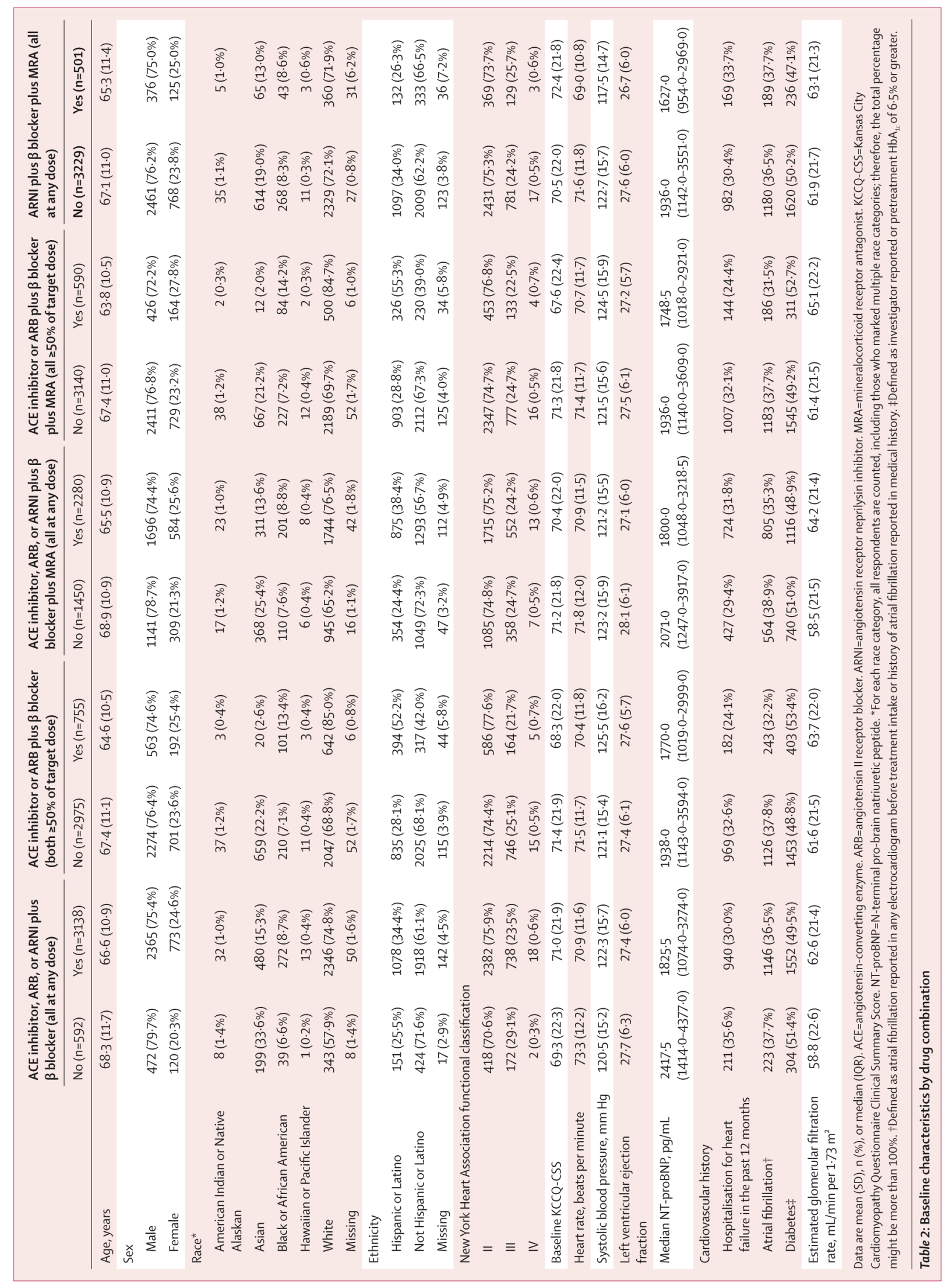


We studied the efficacy of empagliflozin versus placebo in patients given less than $50 \%$ and $50 \%$ or more of target doses of ACE inhibitors, ARBs, $\beta$ blockers, and MRAs. The dose of ARNI was not captured consistently in the trial. The target doses for the various therapies are listed in appendix 2 (p 1), and were established on the basis of updated guidelines. ${ }^{11,12}$ In addition, the treatment effect was evaluated according to whether or not patients were receiving the following therapeutic combinations at baseline: (1) ACE inhibitor, ARB, or ARNI plus $\beta$ blocker all at any dose; (2) ACE inhibitor or ARB plus $\beta$ blocker, both at $50 \%$ or more of target dose; (3) ACE inhibitor, ARB, or ARNI plus $\beta$ blocker plus MRA all at any dose; (4) ACE inhibitor or ARB plus $\beta$ blocker plus MRA, all at $50 \%$ or more of target dose, and (5) ARNI plus $\beta$ blocker plus MRA all at any dose.

\section{Statistical analysis}

The sample size for EMPEROR-Reduced was calculated for detection of a $20 \%$ reduction in the relative risk of the primary outcome with a power of $90 \%$; the trial was not powered for this post-hoc analysis. Baseline characteristics were summarised as means with SDs, medians with IQRs, or frequencies and percentages. For the primary endpoint and the extended composite, hazard ratios (HRs) with $95 \%$ CIs and two-sided p values were calculated using a Cox proportional hazards model with adjustment for prespecified covariates of age, eGFR, region, diabetes status, sex, and LVEF. For total (first and recurrent) hospitalisations for heart failure, between-group differences were assessed using a joint frailty model, with cardiovascular death as a competing risk. The inclusion of interaction terms into the Cox models enabled for the evaluation of subgroup effect modification on the analysed outcomes. No correction for multiple comparisons was made. An independent data and safety monitoring committee was enlisted to review an interim analysis of safety data and results. Prespecified stopping boundaries were used in this analysis. All analyses were performed using SAS, version 9.4. This study is registered with ClinicalTrials. gov, NCT03057977.

\section{Role of the funding source}

Representatives of Boehringer Ingelheim (BP and $\mathrm{MN}$ ) were involved in the study design, data collection, data analysis, data interpretation, and the preparation, review, and approval of the manuscript.

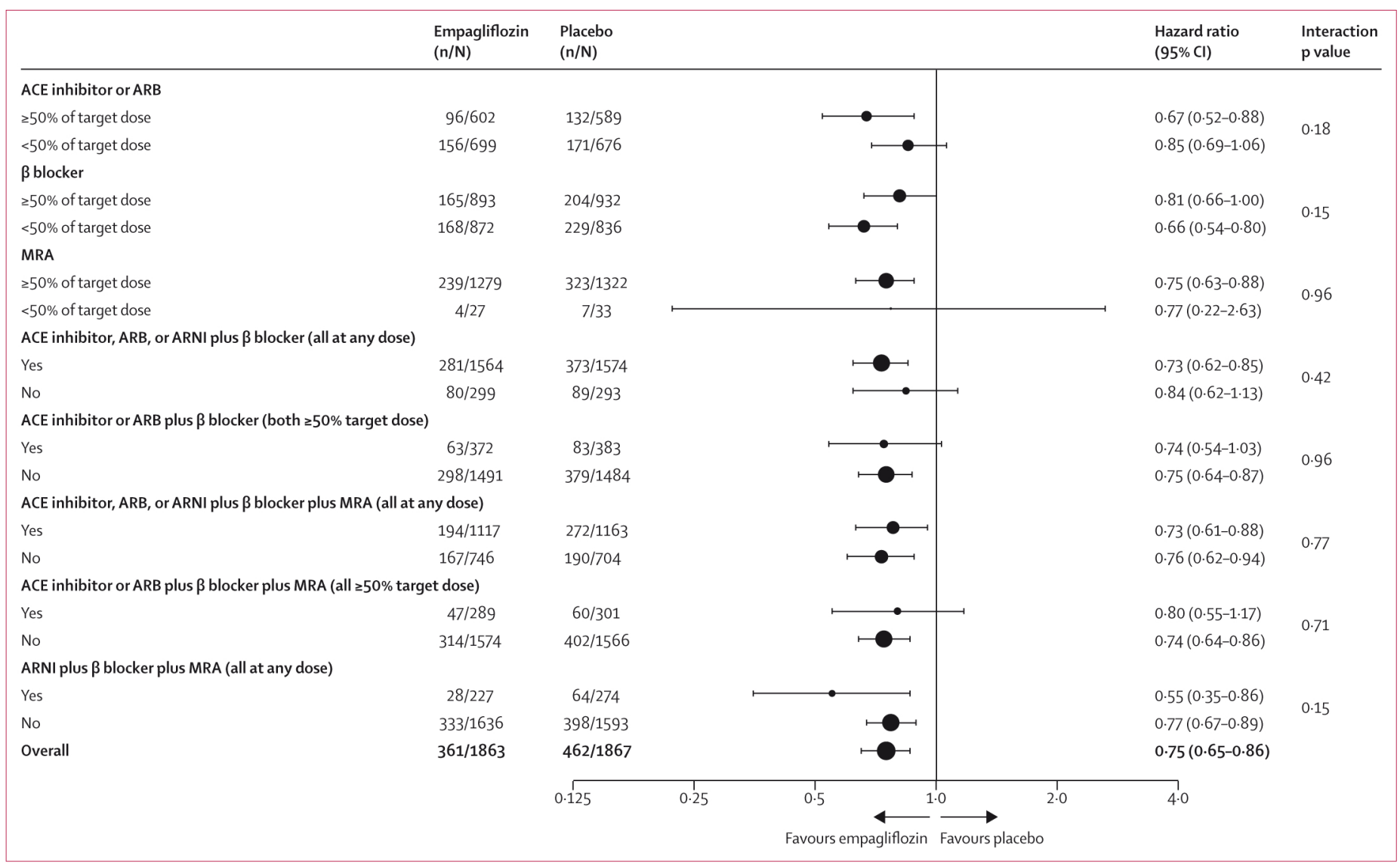




\section{Results}

Between March 6, 2017, and May 28, 2020, of the 3730 patients (mean age 66.8 years [SD 11.0], 893 [23.9\%] women) with HFrEF who were randomly assigned in the EMPEROR-Reduced trial, 1863 (49.9\%) were assigned to receive empagliflozin and 1867 (50.1\%) to receive placebo. Full details regarding patient recruitment and characteristics are available in the primary publication of the trial. ${ }^{4}$ Most patients were receiving an ACE inhibitor, ARB, or ARNI (3293 [88.3\%] of 3730). Of the patients receiving an ACE inhibitor or ARB, 1191 (46.4\%) of 2566 patients were given $50 \%$ or more of the target dose. 3533 (94.7\%) of 3730 patients were taking a $\beta$ blocker, of whom 1825 (51.7\%) patients received $50 \%$ or more of the target dose. Overall, 2661 (71.3\%) of 3730 patients were given an MRA, of whom nearly all (2601 [97.7\%] of 2661) received $50 \%$ or more of the target dose.

With respect to combination therapy, most patients (3138 [84.1\%] of 3730) were given an ACE inhibitor, ARB, or ARNI plus $\beta$ blocker; however, only $20 \cdot 2 \%$ (755 of 3730) of the overall population were given an ACE inhibitor or ARB plus $\beta$ blockers with both at $50 \%$ or more of the target dose. Triple therapy with an ACE inhibitor, ARB, or ARNI plus $\beta$ blocker plus MRA was prescribed in $2280(61.1 \%)$ patients. $501(13.4 \%)$ patients received the triple combination of ARNI, $\beta$ blocker, and MRA. Further details on the proportion of patients in the various subgroups and corresponding baseline characteristics are listed in tables 1 and 2 .

Empagliflozin reduced the risk of the composite of hospitalisations for heart failure or cardiovascular death consistently across baseline drug doses evaluated (figure 1). Specifically, for patients given ACE inhibitors or ARBs at doses of less than $50 \%$ of the target dose, the hazard ratio (HR) for the primary outcome was 0.85 (95\% CI 0.69-1.06) and for doses of 50\% or more of the target dose, the HR for the primary outcome was 0.67 $\left(0.52-0.88 ; p_{\text {interaction }}=0 \cdot 18\right)$. Similarly, for patients given $\beta$ blockers at doses of less than $50 \%$ of the target dose, the HR for the primary outcome was $0.66(0.54-0.80)$ and for doses of $50 \%$ or more of the target dose, the HR for the primary outcome was 0.81 (0.66-1.00; $\left.\mathrm{p}_{\text {interaction }}=0 \cdot 15\right)$. Cumulative incidence curves displaying the time-to-first adjudicated hospitalisations for heart failure or cardiovascular death based on target dose subgroups are provided in appendix 2 (pp 2-4).

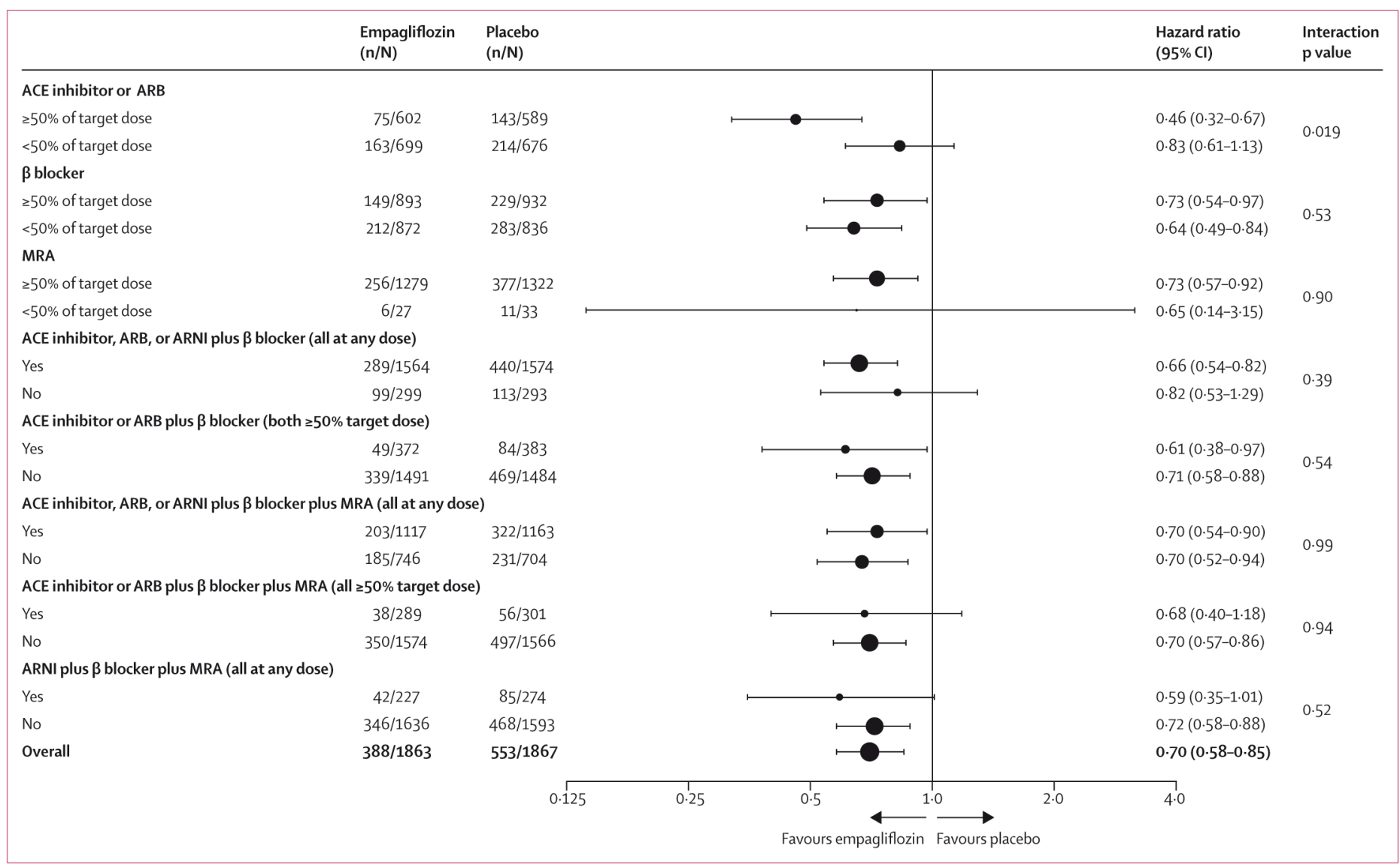

Figure 2: Empagliflozin treatment effect on total hospitalisations for heart failure by background therapy subgroups

$\mathrm{ACE}=$ angiotensin-converting enzyme. $\mathrm{ARB}=$ angiotensin II receptor blocker. $\mathrm{ARN}=$ =angiotensin receptor neprilysin inhibitor. $\mathrm{MRA}=$ mineralocorticoid receptor antagonist. 


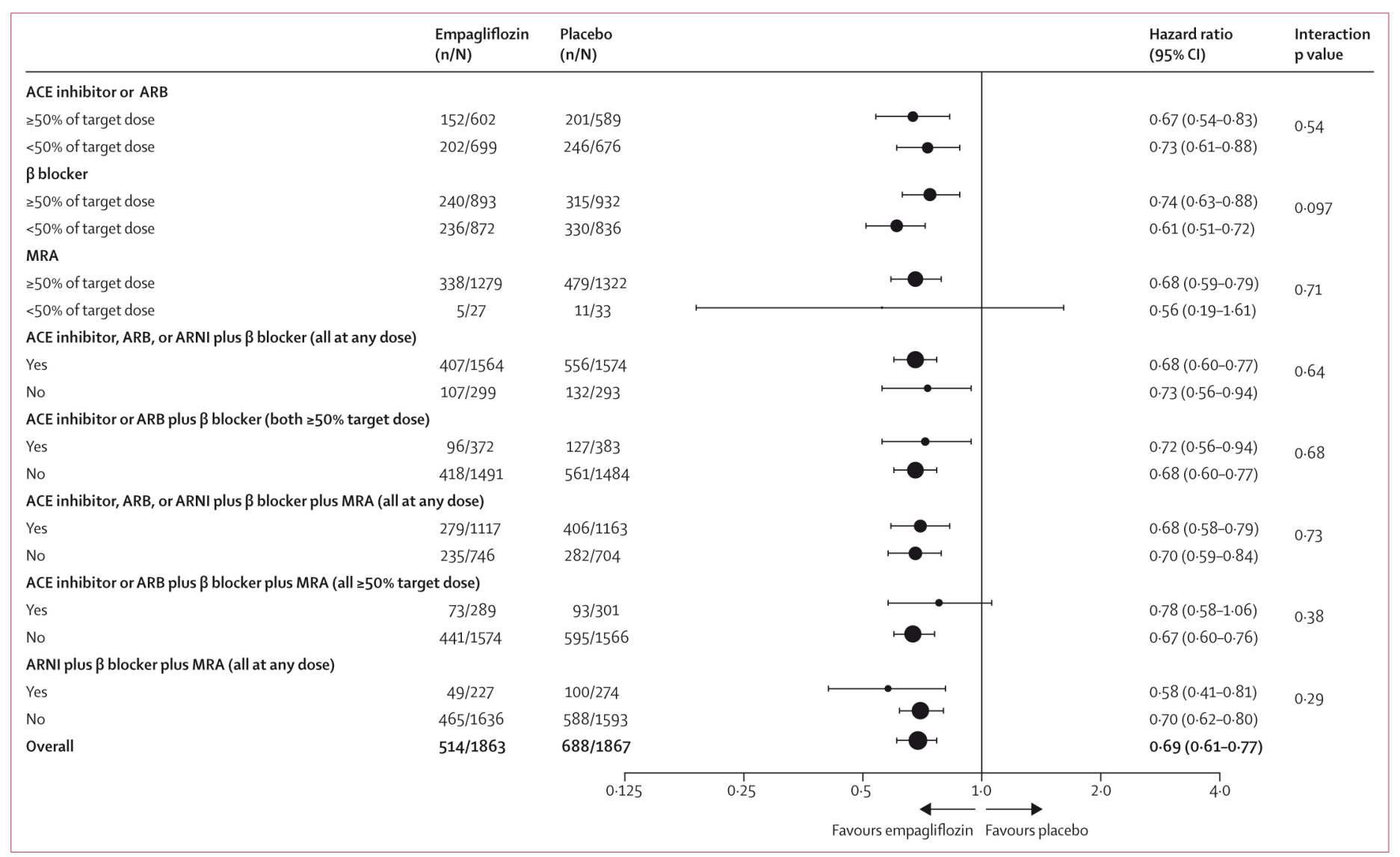

Figure 3: Empagliflozin treatment effect on time to first event of extended composite outcome by background therapy subgroups

$\mathrm{ACE}=$ angiotensin-converting enzyme. $\mathrm{ARB}=$ angiotensin II receptor blocker. $\mathrm{ARN}$ I=angiotensin receptor neprilysin inhibitor. MRA=mineralocorticoid receptor antagonist.

For the secondary endpoint of total hospitalisations for heart failure, there was a nominally significant interaction in patients given ACE inhibitors or ARBs at less than $50 \%$ of target dose (HR 0.83 [95\% CI $0.61-1.13]$ ) or $50 \%$ or more of target dose (HR 0.46 $[0 \cdot 32-0 \cdot 67] ; p_{\text {interaction }}=0 \cdot 019$; figure 2). Consistent benefits were observed for total hospitalisations for heart failure in those prescribed $\beta$ blockers at less than $50 \%$ of target dose (HR $0.64[0.49-0.84]$ ) and $50 \%$ or more of target dose $\left(\right.$ HR $0.73[0.54-0.97] ; p_{\text {interaction }}=0.53$; figure 2$)$. For the extended composite outcome, as shown in figure 3 , empagliflozin's efficacy was observed regardless of the dose of ACE inhibitor, ARB, or $\beta$ blocker.

The effect of empagliflozin on the primary outcome also extended to those patients given clinically relevant dual and triple combinations (figure 1). Of note, in patients given dual therapy with an ACE inhibitor, ARB, or ARNI plus $\beta$ blocker, the HR was 0.73 (95\% CI $0 \cdot 62-0.85)$ favouring empagliflozin, whereas the HR among the remaining patients was $0.84(0 \cdot 62-1 \cdot 13)$; as such, no evidence of heterogeneity was observed between these subgroups $\left(p_{\text {interaction }}=0 \cdot 42\right)$. Moreover, analysis of patients according to baseline treatment with triple therapy with ACE inhibitor, ARB, or ARNI plus $\beta$ blocker plus MRA yielded a consistent benefit of empagliflozin irrespective of whether patients were given this combination therapy or not (given combination HR $0.73 \quad[0.61-0.88]$; not given combination HR $\left.0.76 \quad[0.62-0.94] ; \quad p_{\text {interaction }}=0.77\right)$. Notably, no treatment interaction was observed when comparing patients given triple therapy of ACE inhibitor or ARB plus $\beta$ blocker plus MRA all at $50 \%$ or more of target doses against those that were not (given combination HR 0.80 [0.55-1.17]; not given combination HR 0.74 $\left.[0 \cdot 64-0 \cdot 86] ; p_{\text {interaction }}=0 \cdot 71\right)$. Finally, a consistent benefit favouring empagliflozin was also observed among patients given triple therapy of ARNI plus $\beta$ blocker plus MRA compared with those who were not (given combination HR 0.55 [0.35-0.86]; not given combination HR $\left.0.77[0 \cdot 67-0.89] ; p_{\text {interaction }}=0.15\right)$. The other combinations evaluated also showed a consistent benefit of empagliflozin on the primary outcome (figure 1). The cumulative incidence curves for time-tofirst adjudicated hospitalisations for heart failure or cardiovascular death based on combination therapy subgroups are shown in appendix 2 (pp 5-9).

For the secondary outcome of total hospitalisations for heart failure, empagliflozin's efficacy was observed 


\begin{tabular}{|c|c|c|c|}
\hline & Hypotension* & $\begin{array}{l}\text { Symptomatic } \\
\text { hypotensiont }\end{array}$ & Hyperkalaemia $\ddagger$ \\
\hline \multicolumn{4}{|l|}{ Overall } \\
\hline $\begin{array}{l}\text { Empagliflozin } \\
10 \mathrm{mg}\end{array}$ & $176 / 1863(9 \cdot 4 \%)$ & $106 / 1863(5 \cdot 7 \%)$ & $101 / 1863(5 \cdot 4 \%)$ \\
\hline Placebo & $163 / 1863(8 \cdot 7 \%)$ & $103 / 1863(5 \cdot 5 \%)$ & $115 / 1863(6 \cdot 2 \%)$ \\
\hline \multicolumn{4}{|c|}{ ACE inhibitor or $A R B \geq 50 \%$ of target dose } \\
\hline $\begin{array}{l}\text { Empagliflozin } \\
10 \mathrm{mg}\end{array}$ & $55 / 602(9 \cdot 1 \%)$ & $33 / 602(5 \cdot 5 \%)$ & $47 / 602(7 \cdot 8 \%)$ \\
\hline Placebo & $55 / 589(9 \cdot 3 \%)$ & $34 / 589(5 \cdot 8 \%)$ & $47 / 589(8 \cdot 0 \%)$ \\
\hline \multicolumn{4}{|c|}{ ACE inhibitor or $A R B<50 \%$ of target dose } \\
\hline $\begin{array}{l}\text { Empagliflozin } \\
10 \mathrm{mg}\end{array}$ & $52 / 699(7 \cdot 4 \%)$ & $29 / 699(4 \cdot 1 \%)$ & $29 / 699(4 \cdot 1 \%)$ \\
\hline Placebo & $50 / 672(7 \cdot 4 \%)$ & $28 / 672(4 \cdot 2 \%)$ & $40 / 672(6 \cdot 0 \%)$ \\
\hline \multicolumn{4}{|c|}{$\beta$ blocker $\geq 50 \%$ of target dose } \\
\hline $\begin{array}{l}\text { Empagliflozin } \\
10 \mathrm{mg}\end{array}$ & $81 / 893(9 \cdot 1 \%)$ & $54 / 893(6 \cdot 0 \%)$ & $59 / 893(6 \cdot 6 \%)$ \\
\hline Placebo & $81 / 929(8 \cdot 7 \%)$ & $54 / 929(5 \cdot 8 \%)$ & $61 / 929(6 \cdot 6 \%)$ \\
\hline \multicolumn{4}{|c|}{$\beta$ blocker $<50 \%$ of target dose } \\
\hline $\begin{array}{l}\text { Empagliflozin } \\
10 \mathrm{mg}\end{array}$ & $86 / 872(9 \cdot 9 \%)$ & $45 / 872(5 \cdot 2 \%)$ & $43 / 872(4.9 \%)$ \\
\hline Placebo & $73 / 835(8 \cdot 7 \%)$ & $43 / 835(5 \cdot 1 \%)$ & $63 / 835(7 \cdot 5 \%)$ \\
\hline \multicolumn{4}{|c|}{ MRA $\geq 50 \%$ of target dose } \\
\hline $\begin{array}{l}\text { Empagliflozin } \\
10 \mathrm{mg}\end{array}$ & $123 / 1279(9 \cdot 6 \%)$ & $75 / 1279(5 \cdot 9 \%)$ & $76 / 1279(5 \cdot 9 \%)$ \\
\hline Placebo & $109 / 1319(8 \cdot 3 \%)$ & $69 / 1319(5 \cdot 2 \%)$ & $91 / 1319(6 \cdot 9 \%)$ \\
\hline \multicolumn{4}{|c|}{ MRA $<50 \%$ of target dose } \\
\hline $\begin{array}{l}\text { Empagliflozin } \\
10 \mathrm{mg}\end{array}$ & $4 / 27(14 \cdot 8 \%)$ & $3 / 27(11 \cdot 1 \%)$ & $2 / 27(7 \cdot 4 \%)$ \\
\hline Placebo & $3 / 32(9 \cdot 4 \%)$ & $2 / 32(6 \cdot 3 \%)$ & $4 / 32(12 \cdot 5 \%)$ \\
\hline \multicolumn{4}{|c|}{ Received ACE inhibitor, ARB, or ARNI plus $\beta$ blocker (all at any dose) } \\
\hline $\begin{array}{l}\text { Empagliflozin } \\
10 \mathrm{mg}\end{array}$ & $145 / 1564(9 \cdot 3 \%)$ & $88 / 1564(5 \cdot 6 \%)$ & $89 / 1564(5 \cdot 7 \%)$ \\
\hline Placebo & $135 / 1570(8 \cdot 6 \%)$ & $84 / 1570(5 \cdot 4 \%)$ & $115 / 1570(7 \cdot 3 \%)$ \\
\hline \multicolumn{4}{|c|}{$\begin{array}{l}\text { Did not receive ACE inhibitor, ARB, or ARNI plus } \beta \text { blocker (all at any } \\
\text { dose) }\end{array}$} \\
\hline $\begin{array}{l}\text { Empagliflozin } \\
10 \mathrm{mg}\end{array}$ & $31 / 299(10 \cdot 4 \%)$ & $18 / 299(6 \cdot 0 \%)$ & $20 / 299(6 \cdot 7 \%)$ \\
\hline Placebo & $28 / 293(9 \cdot 6 \%)$ & $19 / 293(6 \cdot 5 \%)$ & $12 / 293(4 \cdot 1 \%)$ \\
\hline \multicolumn{4}{|c|}{$\begin{array}{l}\text { Received ACE inhibitor or ARB plus } \beta \text { blocker (both } \geq 50 \% \text { of target } \\
\text { dose) }\end{array}$} \\
\hline $\begin{array}{l}\text { Empagliflozin } \\
10 \mathrm{mg}\end{array}$ & $37 / 372(9 \cdot 9 \%)$ & $24 / 372(6 \cdot 5 \%)$ & $29 / 372(7 \cdot 8 \%)$ \\
\hline Placebo & $29 / 383(7 \cdot 6 \%)$ & $21 / 383(5 \cdot 5 \%)$ & $30 / 383(7 \cdot 8 \%)$ \\
\hline \multicolumn{4}{|c|}{$\begin{array}{l}\text { Did not receive ACE inhibitor or ARB plus } \beta \text { blocker (both } \geq 50 \% \text { of } \\
\text { target dose) }\end{array}$} \\
\hline $\begin{array}{l}\text { Empagliflozin } \\
10 \mathrm{mg}\end{array}$ & $139 / 1491(9 \cdot 3 \%)$ & $82 / 1491(5 \cdot 5 \%)$ & $80 / 1491(5 \cdot 4 \%)$ \\
\hline \multirow[t]{2}{*}{ Placebo } & $134 / 1480(9 \cdot 1 \%)$ & $82 / 1480(5 \cdot 5 \%)$ & $97 / 1480(6 \cdot 6 \%)$ \\
\hline & & \multicolumn{2}{|c|}{ (Table 3 continues in next column) } \\
\hline
\end{tabular}

regardless of combination therapy (figure 2). Specifically, the HR for patients given dual therapy with an ACE inhibitor, ARB, or ARNI plus $\beta$ blocker was 0.66 (95\% CI $0.54-0.82)$ and $0.82(0.53-1.29)$ for those not given dual therapy $\left(\mathrm{p}_{\text {interaction }}=0.39\right)$. Similarly, patients given triple therapy with an ACE inhibitor, ARB, or ARNI plus $\beta$ blocker plus MRA had an HR of $0.70(0 \cdot 54-0 \cdot 90)$,

\begin{tabular}{|c|c|c|c|}
\hline & Hypotension* & $\begin{array}{l}\text { Symptomatic } \\
\text { hypotension } \dagger\end{array}$ & Hyperkalaemia $\ddagger$ \\
\hline \multicolumn{4}{|c|}{ (Continued from previous column) } \\
\hline \multicolumn{4}{|c|}{$\begin{array}{l}\text { Received ACE inhibitor, ARB, or ARNi plus } \beta \text { blocker plus MRA (all at } \\
\text { any dose) }\end{array}$} \\
\hline $\begin{array}{l}\text { Empagliflozin } \\
10 \mathrm{mg}\end{array}$ & $109 / 1117(9 \cdot 8 \%)$ & $67 / 1117(6 \cdot 0 \%)$ & $66 / 1117(5 \cdot 9 \%)$ \\
\hline Placebo & $93 / 1159(8.0 \%)$ & $58 / 1159(5 \cdot 0 \%)$ & $89 / 1159(7 \cdot 7 \%)$ \\
\hline \multicolumn{4}{|c|}{$\begin{array}{l}\text { Did not receive ACE inhibitor, ARB, or ARNi plus } \beta \text { blocker plus MRA } \\
\text { (all at any dose) }\end{array}$} \\
\hline $\begin{array}{l}\text { Empagliflozin } \\
10 \mathrm{mg}\end{array}$ & $67 / 746(9 \cdot 0 \%)$ & $39 / 746(5 \cdot 2 \%)$ & $43 / 746(5 \cdot 8 \%)$ \\
\hline Placebo & $70 / 704(9 \cdot 9 \%)$ & $45 / 704(6 \cdot 4 \%)$ & $38 / 704(5 \cdot 4 \%)$ \\
\hline \multicolumn{4}{|c|}{$\begin{array}{l}\text { Received ACE inhibitor or ARB plus } \beta \text { blocker plus MRA (all } \geq 50 \% \text { of } \\
\text { target dose) }\end{array}$} \\
\hline $\begin{array}{l}\text { Empagliflozin } \\
10 \mathrm{mg}\end{array}$ & $33 / 289(11 \cdot 4 \%)$ & $22 / 289(7 \cdot 6 \%)$ & $25 / 289(8 \cdot 7 \%)$ \\
\hline Placebo & $22 / 301(7 \cdot 3 \%)$ & $16 / 301(5 \cdot 3 \%)$ & $22 / 301(7 \cdot 3 \%)$ \\
\hline \multicolumn{4}{|c|}{$\begin{array}{l}\text { Did not receive ACE inhibitor or ARB plus } \beta \text { blocker plus MRA (all } \geq 50 \% \\
\text { of target dose) }\end{array}$} \\
\hline $\begin{array}{l}\text { Empagliflozin } \\
10 \mathrm{mg}\end{array}$ & $143 / 1574(9 \cdot 1 \%)$ & $84 / 1574(5 \cdot 3 \%)$ & $84 / 1574(5 \cdot 3 \%)$ \\
\hline Placebo & $141 / 1562(9 \cdot 0 \%)$ & $87 / 1562(5 \cdot 6 \%)$ & $105 / 1562(6 \cdot 7 \%)$ \\
\hline \multicolumn{4}{|c|}{ Received ARNI plus $\beta$ blocker plus MRA (all at any dose) } \\
\hline $\begin{array}{l}\text { Empagliflozin } \\
10 \mathrm{mg}\end{array}$ & $31 / 227(13 \cdot 7 \%)$ & $21 / 227(9 \cdot 3 \%)$ & $12 / 227(5 \cdot 3 \%)$ \\
\hline Placebo & $27 / 274(9 \cdot 9 \%)$ & $19 / 274(6 \cdot 9 \%)$ & $22 / 274(8 \cdot 0 \%)$ \\
\hline \multicolumn{4}{|c|}{ Did not receive ARNI plus $\beta$ blocker plus MRA (all at any dose) } \\
\hline $\begin{array}{l}\text { Empagliflozin } \\
10 \mathrm{mg}\end{array}$ & $145 / 1636(8.9 \%)$ & $85 / 1636(5 \cdot 2 \%)$ & $97 / 1636(5 \cdot 9 \%)$ \\
\hline Placebo & $136 / 1589(8 \cdot 6 \%)$ & $84 / 1589(5 \cdot 3 \%)$ & $105 / 1589(6 \cdot 6 \%)$ \\
\hline \multicolumn{4}{|c|}{ 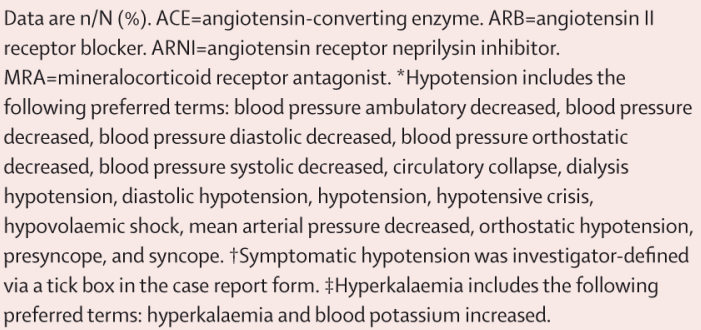 } \\
\hline
\end{tabular}

while those that were not had an HR of $0 \cdot 70(0 \cdot 52-0 \cdot 94$; $\mathrm{p}_{\text {interaction }}=0.99$ ). As shown in figure 3 , a consistent benefit on the rates of the extended composite outcome was also noted regardless of treatment with the combination therapy of ACE inhibitor, ARB, or ARNI plus $\beta$ blocker or ACE inhibitor, ARB, or ARNI plus $\beta$ blocker plus MRA.

Occurrences of select adverse events are shown in table 3. Details of adverse events in the EMPERORReduced trial have been published elsewhere. ${ }^{4}$ Uncomplicated genital tract infections were reported more frequently in the empagliflozin versus placebo treatment groups. The frequency of bone fracture, hypoglycaemia, and lower limb amputation did not differ between the two groups. Safety concerns that have been 
reported with other drugs for heart failure were not observed with empagliflozin in this trial. ${ }^{4}$ As documented in table 3 , rates of hypotension, symptomatic hypotension, and hyperkalaemia appeared largely similar in all subgroups studied, regardless of randomisation to empagliflozin or placebo.

\section{Discussion}

The current analyses were conducted to ascertain whether the classes and dosage of background therapies influenced the efficacy of empagliflozin on heart failure outcomes in patients with HFrEF. We focused on disease-modifying heart failure therapies, namely, ACE inhibitors, ARBs, ARNIs, $\beta$ blockers, and MRAs. We report a consistent benefit of empagliflozin on the primary outcome of hospitalisations for heart failure or cardiovascular death irrespective of background use of these therapies at less than $50 \%$ or $50 \%$ or more of target dose, and in various clinically relevant dual and triple combinations. Similarly, the efficacy of empagliflozin for the key secondary outcome of total heart failure hospitalisations and for the extended composite consisting of inpatient and outpatient worsening heart failure events, was consistent across the analysed subgroups. Lastly, regardless of treatment with combination therapy or doses of $50 \%$ or greater or less than $50 \%$ of target dose, empagliflozin was well tolerated. Taken together, these data indicate that empagliflozin provides clinically important benefits in HFrEF in addition to existing disease-modifying therapies, regardless of breadth or intensity of use.

Our data extend the observations made in the DAPA-HF

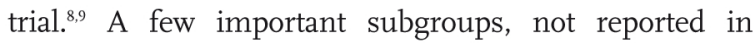
DAPA-HF, have been included in the current analyses. These include the very commonly used dual combination of an ACE inhibitor, ARB, or ARNI plus $\beta$ blocker, wherein we show a consistent benefit of empagliflozin. In addition, we also report on the subgroup of patients given triple therapy of ACE inhibitor or ARB plus a $\beta$ blocker plus MRA, all at $50 \%$ or more of target doses. Here, too, we found no evidence of heterogeneity with respect to the primary, secondary, or exploratory outcomes. Triple therapy with an ARNI plus $\beta$ blocker plus MRA is considered to be the most beneficial pharmacotherapeutic combination in HFrEF. Therefore, understanding whether SGLT2 inhibitors are effective in addition to this combination is of clinical importance. In DAPA-HF, only a small proportion of patients $(6.9 \%)$ were given this triple therapy combination, compared with $15 \%$ in EMPEROR-Reduced. Analysis of patients stratified by baseline treatment with this therapeutic combination once again yielded no evidence of heterogeneity in any of the investigated outcomes and the four-treatment regimen was well tolerated. The current analyses also report on the key secondary outcome of total hospitalisations for heart failure, and the extended composite outcome (of worsening inpatient or outpatient heart failure events), which were not reported in DAPA-HF.
The current analyses have important clinical implications. First, they emphasise that background therapy does not influence the response to empagliflozin in HFrEF. This observation points to a complementary mechanism of action in HFrEF and is reassuring, as in clinical practice, patients frequently have a heterogeneous mixture of doses for their guideline-directed medical therapy. Our results suggest that achieving four-drug treatment is associated with benefit, even if sub-target doses of each therapy are necessary due to hypotension or other challenges. Although several mechanisms of SGLT2 inhibitors have been proposed, ${ }^{13-21}$ it is clear that the benefit is independent of glycaemic status and is maintained even at low eGFR concentrations (down to $20 \mathrm{~mL} / \mathrm{min}$ per $1.73 \mathrm{~m}^{2}$ in EMPEROR-Reduced). Studies from the past few years have also shown that empagliflozin is effective at promoting reverse cardiac remodelling in patients with and without diabetes or heart failure when added to background therapies. ${ }^{22-25}$ Although ACE inhibitors, ARBs, or ARNIs, $\beta$ blockers, and MRAs exert their benefits through inhibition of angiotensin-II signalling, noradrenaline, and aldosterone activation, respectively, SGLT2 inhibitors have been suggested to favourably affect remodelling via augmenting nutrient deprivation signalling, which in turn might improve cardiomyocyte function and survival. ${ }^{13,26,27}$

These data also suggest that empagliflozin can be added irrespective of other therapies in HFrEF-the benefits are neither dependent upon treatment greater or less than $50 \%$ of target dose, nor modulated by any combination of disease-modifying therapies. A growing body of evidence suggests that patients with HFrEF derive the bulk of their cardiovascular benefit at starting or lower doses of therapy, and that further dose escalation serves to primarily reduce non-fatal outcomes only. ${ }^{26,28-35}$ Thus, understanding the effect of empagliflozin among patients treated at these sub-target doses is of particular clinical relevance.

The analyses should be interpreted in light of the following limitations. First, the subanalyses were post hoc; therefore, the results presented herein should be considered exploratory and hypothesis-generating. Second, multiplicity of comparisons might inflate the false positive error rate. Third, the absence of available data for prescribed ARNI doses prevented analysis of patients on the basis of this parameter. Fourth, rates of adherence and therapeutic changes are not available in these analyses. Fifth, the relatively few patients included in some of the presently analysed subgroups prevent firm conclusions from being drawn. Finally, the background therapies investigated herein were not randomised and were thus prescribed based on patientspecific characteristics, prescriber patterns, and regional guidelines and recommendations. As such, important differences could exist between the studied subgroups. 
To conclude, in the EMPEROR-Reduced randomised trial, we found that empagliflozin's efficacy in HFrEF was maintained regardless of background therapy doses and combinations of heart failure medications. As such, empagliflozin should be considered as a potential therapy in patients with HFrEF irrespective of their existing background therapy.

\section{Contributors}

SV, MP, BP, and MN were responsible for study concept and design. $\mathrm{BP}$ was responsible for acquisition of data. SV, MP, and BP were responsible for the analysis and interpretation of data. SV and MP had full access to all of the data in the study and take responsibility for the integrity of the data and the accuracy of the data analysis. SV, NKD, and MP were responsible for drafting of the manuscript. All authors were responsible for critical revision of the manuscript for important intellectual content. $\mathrm{BP}$ was responsible for statistical analysis. MP obtained funding. MP and $\mathrm{SV}$ were responsible for supervision. The decision to submit the manuscript for publication was taken by the academic leadership of the steering committee (JB, SDA, JPF, GF, SJP, FZ, and MP).

\section{Declaration of interests}

SV holds a tier 1 Canada Research Chair in cardiovascular surgery; and reports receiving research grants and honoraria from Amarin, Amgen, AstraZeneca, Bayer, Boehringer Ingelheim, Bristol-Myers Squibb, Eli Lilly, HLS Therapeutics, Janssen, Novartis, Novo Nordisk, PhaseBio, and Pfizer; and receiving honoraria from Sanofi, Sun Pharmaceuticals, and the Toronto Knowledge Translation Working Group. He is a member of the scientific excellence committee of the EMPERORReduced trial and served as a national lead investigator of the DAPA-HF and EMPEROR-Reduced trials. He is the President of the Canadian Medical and Surgical Knowledge Translation Research Group, a federally incorporated not-for-profit physician organisation. JB reports consulting fees from Boehringer Ingelheim, Cardior, CVRx, Foundry, G3 Pharma, Imbria, Impulse Dynamics, Innolife, Janssen, LivaNova, Luitpold, Medtronic, Merck, Novartis, NovoNordisk, Relypsa, Roche, Sanofi, Sequana Medical, V-Wave, and Vifor. SDA has received grants from Vifor; personal fees from Vifor, Bayer, Boehringer Ingelheim, Novartis, Servier, Impulse Dynamics, Cardiac Dimensions, and Thermo Fisher Scientific; and grants and personal fees from Abbott Vascular. JPF reports consulting fees from Boehringer Ingelheim. GF reports honoraria for lectures for Medtronic, Vifor, Servier, Novartis, Bayer, Amgen, and Boehringer Ingelheim, and committee member contributions in trials sponsored by Boehringer Ingelheim. JLJ reports grant support, consulting income, and participation in clinical endpoint committees and data safety monitoring boards from Janssen; participation in clinical endpoint committees and data safety monitoring boards from Boehringer Ingelheim; grant support from Novartis, Innolife, Applied Therapeutics, and Siemens Diagnostics; and consultancy fees from Novartis, Roche Diagnostics, and Abbott Diagnostics. CSPL reports research grants from Bayer, Boston Scientific, Roche Diagnostic, Medtronic, Vifor Pharma, and AstraZeneca; consulting fees from Merck, Bayer, Boston Scientific, Roche Diagnostic, Vifor Pharma, AstraZeneca, Novartis, Amgen, Janssen Research and Development, Menarini, Boehringer Ingelheim, Abbott Diagnostics, Corvia, Stealth BioTherapeutics, Novo Nordisk, JanaCare, Biofourmis, Darma, Applied Therapeutics, MyoKardia, Cytokinetics, WebMD Global, Radcliffe Group, and Corpus; and serves as co-founder and non-executive director of eKo.ai. NS reports personal fees from Amgen, AstraZeneca, Boehringer Ingelheim, Eli Lilly, MSD, Novo Nordisk, Pfizer, and Sanofi; and grant income from Boehringer Ingelheim. BP, MN, and MB are employees of Boehringer Ingelheim. SJP reports personal fees from Boehringer Ingelheim. FZ reports personal fees from Boehringer Ingelheim, Janssen, Novartis, Boston Scientific, Amgen, CVRx, AstraZeneca, Vifor Fresenius, Cardior, Cereno Pharmaceutical, Applied Therapeutics, Merck, Bayer, and Cellprothera; and other support from cardiovascular clinical trialists and Cardiorenal. MP reports personal fees from AbbVie, Actavis, Amgen, Amarin, AstraZeneca, Boehringer Ingelheim, Bristol Myers Squibb, Casana, CSL Behring, Cytokinetics, Johnson \& Johnson, Lilly, Moderna, Novartis, ParatusRx, Pfizer, Relypsa, Salamandra, Synthetic Biologics, and Theravance. NKD declares no competing interests.

\section{Data sharing}

Data related to this manuscript will be made available upon request in adherence with transparency conventions in medical research and through requests to the corresponding author. The executive committee of EMPEROR has developed a comprehensive analysis plan and numerous prespecified analyses, which will be presented in future scientific presentations and publications. At a later timepoint, the full database will be made available in adherence with the ratified transparency policy.

\section{Acknowledgments}

Graphical assistance, supported financially by Boehringer Ingelheim, was provided by Sally Neath and Charlie Bellinger of Elevate Scientific Solutions.

\section{References}

1 Greene SJ, Butler J, Albert NM, et al. Medical therapy for heart failure with reduced ejection fraction: the CHAMP-HF registry. J Am Coll Cardiol 2018; 72: 351-66.

2 Fiuzat M, Ezekowitz J, Alemayehu W, et al. Assessment of limitations to optimization of guideline-directed medical therapy in heart failure from the GUIDE-IT trial: a secondary analysis of a randomized clinical trial. JAMA Cardiol 2020; 5: 757-64.

3 Abraham WT, Psotka MA, Fiuzat M, et al. Standardized definitions for evaluation of heart failure therapies: scientific expert panel from the heart failure collaboratory and academic research consortium. JACC Heart Fail 2020; 8: 961-72.

4 Packer M, Anker SD, Butler J, et al. Cardiovascular and renal outcomes with empagliflozin in heart failure. N Engl J Med 2020; 383: 1413-24.

5 Anker SD, Butler J, Filippatos G, et al. Effect of empagliflozin on cardiovascular and renal outcomes in patients with heart failure by baseline diabetes status: results from the EMPEROR-Reduced trial. Circulation 2021; 143: 337-49

6 Zannad F, Ferreira JP, Pocock SJ, et al. Cardiac and kidney benefits of empagliflozin in heart failure across the spectrum of kidney function: insights from EMPEROR-Reduced. Circulation 2021; 143: 310-21.

7 Lam CSP, Ferreira JP, Pfarr E, et al. Regional and ethnic influences on the response to empagliflozin in patients with heart failure and a reduced ejection fraction: the EMPEROR-Reduced trial. Eur Heart J 2021; published online June 29. https://doi.org/10.1093/eurhearti/ ehab360.

8 McMurray JJV, Solomon SD, Inzucchi SE, et al. Dapagliflozin in patients with heart failure and reduced ejection fraction. N Engl J Med 2019; 381: 1995-2008.

9 Docherty KF, Jhund PS, Inzucchi SE, et al. Effects of dapagliflozin in DAPA-HF according to background heart failure therapy. Eur Heart J 2020; 41: 2379-92.

10 Packer M, Butler J, Filippatos GS, et al. Evaluation of the effect of sodium-glucose co-transporter 2 inhibition with empagliflozin on morbidity and mortality of patients with chronic heart failure and a reduced ejection fraction: rationale for and design of the EMPEROR-Reduced trial. Eur J Heart Fail 2019; 21: 1270-78.

11 Yancy CW, Jessup M, Bozkurt B, et al. 2013 ACCF/AHA guideline for the management of heart failure: a report of the American College of Cardiology Foundation/American Heart Association Task Force on Practice Guidelines. J Am Coll Cardiol 2013; 62: e147-239.

12 Ponikowski P, Voors AA, Anker SD, et al. 2016 ESC Guidelines for the diagnosis and treatment of acute and chronic heart failure: the task force for the diagnosis and treatment of acute and chronic heart failure of the European Society of Cardiology (ESC)Developed with the special contribution of the Heart Failure Association (HFA) of the ESC. Eur Heart J 2016; 37: 2129-200.

13 Packer M. SGLT2 inhibitors produce cardiorenal benefits by promoting adaptive cellular reprogramming to induce a state of fasting mimicry: a paradigm shift in understanding their mechanism of action. Diabetes Care 2020; 43: 508-11.

14 Packer M. Critical examination of mechanisms underlying the reduction in heart failure events with SGLT2 inhibitors: identification of a molecular link between their actions to stimulate erythrocytosis and to alleviate cellular stress. Cardiovasc Res 2021; 117: 74-84.

15 Packer M. Reconceptualization of the molecular mechanism by which sodium-glucose cotransporter 2 inhibitors reduce the risk of heart failure events. Circulation 2019; 140: 443-45. 
16 Packer M, Anker SD, Butler J, Filippatos G, Zannad F. Effects of sodium-glucose cotransporter 2 inhibitors for the treatment of patients with heart failure: proposal of a novel mechanism of action. JAMA Cardiol 2017; 2: 1025-29.

17 Packer M. Autophagy stimulation and intracellular sodium reduction as mediators of the cardioprotective effect of sodiumglucose cotransporter 2 inhibitors. Eur J Heart Fail 2020; 22: 618-28.

18 Lopaschuk GD, Verma S. Mechanisms of cardiovascular benefits of sodium glucose co-transporter 2 (SGLT2) inhibitors: a state-of-theart review. JACC Basic Transl Sci 2020; 5: 632-44.

19 Vallon V, Verma S. Effects of SGLT2 Inhibitors on Kidney and Cardiovascular Function. Annu Rev Physiol 2021; 83: 503-28.

20 Verma S, McMurray JJV. SGLT2 inhibitors and mechanisms of cardiovascular benefit: a state-of-the-art review. Diabetologia 2018; 61: 2108-17.

21 Jensen J, Omar M, Kistorp C, et al. Effects of empagliflozin on estimated extracellular volume, estimated plasma volume, and measured glomerular filtration rate in patients with heart failure (Empire HF Renal): a prespecified substudy of a double-blind, randomised, placebo-controlled trial. Lancet Diabetes Endocrinol 2021; 9: 106-16.

22 Verma S, Mazer CD, Yan AT, et al. Effect of empagliflozin on left ventricular mass in patients with type 2 diabetes mellitus and coronary artery disease: the EMPA-HEART cardiolink-6 randomized clinical trial. Circulation 2019; 140: 1693-702.

23 Lee MMY, Brooksbank KJM, Wetherall K, et al. Effect of empagliflozin on left ventricular volumes in patients with type 2 diabetes, or prediabetes, and heart failure with reduced ejection fraction (SUGAR-DM-HF). Circulation 2021; 143: 516-25.

24 Santos-Gallego CG, Vargas-Delgado AP, Requena-Ibanez JA, et al. Randomized trial of empagliflozin in nondiabetic patients with heart failure and reduced ejection fraction. J Am Coll Cardiol 2021; 77: 243-55.

25 Omar M, Jensen J, Ali M, et al. Associations of empagliflozin with left ventricular volumes, mass, and function in patients with heart failure and reduced ejection fraction: a substudy of the Empire HF randomized clinical trial. JAMA Cardiol 2021; 6: 836-40.
26 Packer M, McMurray JJV. Rapid evidence-based sequencing of foundational drugs for heart failure and a reduced ejection fraction. Eur J Heart Fail 2021; 23: 882-94.

27 Avogaro A, Fadini GP, Del Prato S. Reinterpreting cardiorenal protection of renal sodium-glucose cotransporter 2 inhibitors via cellular life history programming. Diabetes Care 2020; 43: 501-07.

28 Packer M, Poole-Wilson PA, Armstrong PW, et al. Comparative effects of low and high doses of the angiotensin-converting enzyme inhibitor, lisinopril, on morbidity and mortality in chronic heart failure. Circulation 1999; 100: 2312-18.

29 Lam PH, Packer M, Fonarow GC, et al. Early effects of starting doses of enalapril in patients with chronic heart failure in the SOLVD Treatment trial. Am J Med 2020; 133: e25-31.

30 Krum H, Roecker EB, Mohacsi P, et al. Effects of initiating carvedilol in patients with severe chronic heart failure: results from the COPERNICUS Study. JAMA 2003; 289: 712-18.

31 Pitt B, White H, Nicolau J, et al. Eplerenone reduces mortality 30 days after randomization following acute myocardial infarction in patients with left ventricular systolic dysfunction and heart failure. J Am Coll Cardiol 2005; 46: 425-31.

32 Konstam MA, Neaton JD, Dickstein K, et al. Effects of high-dose versus low-dose losartan on clinical outcomes in patients with heart failure (HEAAL study): a randomised, double-blind trial. Lancet 2009; 374: 1840-48.

33 Ferreira JP, Abreu P, McMurray JJV, et al. Renal function stratified dose comparisons of eplerenone versus placebo in the EMPHASIS HF trial. Eur J Heart Fail 2019; 21: 345-51.

34 Bristow MR, Gilbert EM, Abraham WT, et al. Carvedilol produces dose-related improvements in left ventricular function and survival in subjects with chronic heart failure. Circulation 1996; 94: 2807-16.

35 Vardeny O, Claggett B, Packer M, et al. Efficacy of sacubitril/ valsartan vs. enalapril at lower than target doses in heart failure with reduced ejection fraction: the PARADIGM-HF trial. Eur J Heart Fail 2016; 18: 1228-34. 